\title{
Evaluación superficial de vías urbanas empleando vehículo aéreo no tripulado (VANT)
}

Pavement surface evaluation of urban roads using an unmanned aerial vehicle (UAV)

Ing. Jorge Omar Cruz Toribio

Estudiante Ingeniería Civil

Universidad Nacional de Ingeniería, Perú

jcruzt@uni.pe
Ing. M.Sc. José Wilfredo Gutiérrez Lazares

Decano Facultad de Ingeniería

Universidad Nacional de Ingeniería, Perú

ghama@speedy.com.pe

Fecha de recepción: 26 julio 2018 / Fecha de aprobación: 20 marzo 2019

Índices y Bases de Datos:

lationdex UcRIndex

\section{Dialnet DOAJ}

(2) revistas.ucr.ac.cr/index.php/materiales

(e) lanamme.ucr.ac.cr

@ metodosymateriales.lanamme@ucr.ac.cr
Políticas de Uso:

\section{(cC)}

Revista Métodos y Materiales por LanammeUCR se distribuye bajo: Licencia Creative Commons Atribución-NoComercialSinDerivar 4.0 Internacional. ISSN electrónico: 2215-4558 


\section{Evaluación superficial de vías urbanas empleando vehículo aéreo no tripulado (VANT)}

\section{Pavement surface evaluation of urban roads using an unmanned aerial vehicle (UAV)}

\author{
Ing. Jorge Omar Cruz Toribio \\ Estudiante Ingeniería Civil \\ Universidad Nacional de Ingeniería, Perú \\ jcruzt@uni.pe
}

\author{
Ing. M.Sc. José Wilfredo Gutiérrez Lazares \\ Decano Facultad de Ingeniería \\ Universidad Nacional de Ingeniería, Perú \\ ghama@speedy.com.pe
}

Fecha de recepción: 26 julio 2018 / Fecha de aprobación: 20 marzo 2019

\section{RESUMEN}

El presente trabajo de investigación expone una metodología alternativa para la evaluación superficial de pavimentos en vías urbanas, empleando imágenes georreferenciadas, obtenidas por un vehículo aéreo no tripulado (VANT) que se procesan generando una ortofoto y un modelo digital 3D de alta resolución. El análisis de los productos generados permite la inspección total de la vía de manera segura, identificando el tipo de deterioro, su severidad y su densidad dañada, como parámetros e insumos para emplear el Método PavementConditionlndex (PCI). Los resultados que se obtienen en una vía de prueba, demuestran que el método VANT recoge datos de manera más segura, permite planos de mayor información con valores fidedignos y evita accidentes del personal técnico en comparación con el método tradicional. Esta investigación innova un procedimiento alternativo para evaluar pavimentos periódicamente con fines de establecer estrategias de mantenimiento y rehabilitación de las vías urbanas.

\begin{abstract}
This research paper presents an alternative methodology for the surface evaluation of pavements on urban roads, using georeferenced images obtained by an unmanned aerial vehicle (UAV) that are processed by generating an orthophoto and a high-resolution 3D digital model. The analysis of the generated products allows the total inspection of the pavement in a safe way, identifying the type of deterioration, its severity and its damaged density, as parameters and inputs to use the Pavement Condition Index (PCI) Method. The results obtained in a test track show that the VANT method collects data in a safer way, allows more informative plans with reliable values and avoids accidents of the technical staff in comparison with the traditional method. This research innovates an alternative procedure to evaluate pavements periodically in order to establish strategies for maintenance and rehabilitation of urban roads.
\end{abstract}

Keywords: Surface evaluation, UAV, Pavement, PCI.

Palabras clave: Evaluación superficial, VANT, pavimentos, $\mathrm{PCl}$. 


\section{INTRODUCCIÓN}

Las vías urbanas de las principales ciudades del país se encuentran saturadas de vehículos que dificultan los trabajos de mantenimiento que se realizan con urgencia, debido a su mal estado. Por ello los usuarios ven incrementado sus costos de operación los vehículos debido a la falta de gestión, por parte de los municipios, para el mantenimiento de la infraestructura vial. Las Municipalidades al no contar con información sobre el estado de deterioro de las vías, optan por tratamientos superficiales de poca duración, sin un sustento más profundo para atacar la problemática. Es por ello que se realiza la evaluación superficial del pavimento para obtener información potencial del estado situacional de la vía, probables causas de los problemas y su posible solución para planificar los trabajos de mantenimiento y/o rehabilitación (Gutierrez 2016).

Sin embargo, los actuales métodos de inspección en campo e incluso vehículos para la detección de la calidad de las vías son lentos, requieren mucho personal y son costosos. Por lo tanto, el uso de técnicas modernas de bajo costo que permitan hacer el seguimiento de la condición del pavimento de forma eficiente, optimizando los recursos de los gobiernos municipales es una tarea muy importante.

Los Vehículos Aéreos No Tripulados (VANT) comúnmente conocidos como drones, son en esencia pequeñas plataformas aéreas que se operan a distancia o en forma programada. Los mismos ganaron popularidad en el mundo por sus aplicaciones militares, sin embargo, esta tecnología tiene un amplio espectro de usos pacíficos a partir de la obtención de fotografías los cuales después de un tratamiento digital, pueden ser convertidas en ortofotos y modelos 3D (Martinez, et al. 2009). Asimismo, el uso de vehículos aéreos no tripulados de bajo costo, se han empleado en investigaciones para recolectar información de la condición de caminos rurales, obteniendo resultados con buena precisión y confiabilidad (Zhang, Elaksher 2012).

En este sentido, el presente trabajo espera aportar un nuevo procedimiento de evaluación para el monitoreo y conservación de las vías urbanas empleando vehículos aéreos no tripulados, optimizando los recursos de los gobiernos municipales para beneficio de los usuarios.

\section{SITUACIÓN DE LA PROBLEMÁTICA}

La mayoría de los municipios no cuentan con información que les permita elaborar su plan operativo para trabajos anuales.
Entre otras especialidades, se carece de información en cuanto al estado de deterioro en que se encuentran las vías urbanas que administran. La falta de una evaluación superficial o relevamiento de las fallas existentes en los pavimentos, impide realizar una racional planificación de trabajos correctivos, lo que propicia una programación improvisada de medidas correctivas en los pavimentos.

A esto se suma la falta de políticas de inversión y de estrategias adecuadas para el mantenimiento de las vías, generando el deterioro acelerado de la superficie de rodadura y con la consecuente protesta de los usuarios. Por otro lado, el tiempo invertido en los trabajos de evaluación de las vías urbanas se dificulta por el intenso tráfico que se presenta y que pone en riesgo la vida de los evaluadores o controladores.

\section{JUSTIFICACIÓN}

Los gobiernos municipales necesitan contar con nuevas tecnologías de bajo costo y de buena precisión que permita genera información de la condición del pavimento que le permita planificar, programar, priorizar y presupuestar el mantenimiento y rehabilitación de sus vías, optimizando los recursos disponibles en forma eficiente.

\section{HIPOTESIS}

Empleando vehículos aéreos no tripulados (VANT) se podría realizar eficientemente el inventario y cálculo de las dimensiones de los deterioros de las vías urbanas mejorando los rendimientos en el proceso del método tradicional PCI, sin poner en riesgo la vida humana.

\section{OBJETIVOS}

\subsection{Objetivo General}

- Calcular el Índice de Condición del Pavimento (PCI) en vías urbanas, empleando las imágenes obtenidas con Vehículo Aéreo No Tripulado (VANT)

\subsection{Objetivos Específicos}

- Registrar el estado del pavimento mediante el procesamiento de las imágenes georreferenciadas obtenidas del vehículo aéreo no tripulado. 
- Evaluar las áreas afectadas según el tipo de falla en función de su densidad y severidad, empleando el método del PavementConditionIndex (PCI).

- Determinar las ventajas y desventajas de aplicar la inspección empleando un VANT y el método tradicional del PCI, aplicados en una zona de prueba.

\section{METODOLOGIA Y VIIA DE PRUEBA}

\subsection{Métodos y Materiales}

Entre los instrumentos utilizados, como herramienta para la obtención de fotografías aéreas de la zona de estudio se adquirió un multi-rotor de la marca DJI modelo Phantom 4 Pro que se muestra en la Figura 1, el cual consta principalmente de 4 hélices con una cámara de 20 MP, montada sobre un sistema de giroscopio de estabilización que permite mantener la imagen estable independientemente de los movimientos propios del vuelo y las influencias del viento.

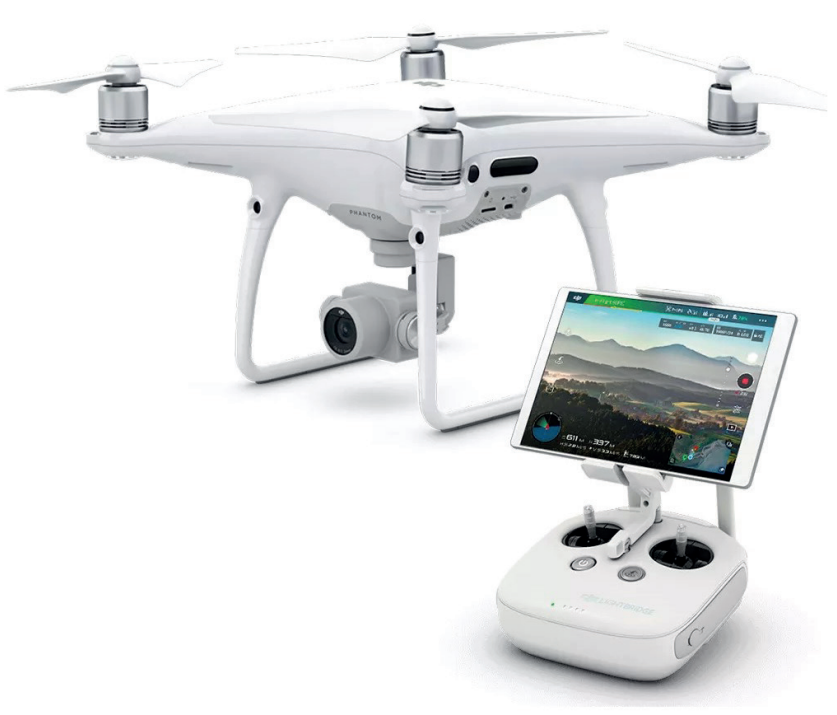

Figura 1. Multirrotor DJI Phantom 4 Pro

Por otro lado, para el procesamiento de imágenes se empleó el software Pix4dMapper Pro instalado en un computador con procesador i7, de $2.8 \mathrm{Ghz}$ y de $16 \mathrm{~GB}$ de memoria RAM, cuya salida es el modelo digital de superficie en 3D y la ortofoto para proceder a la inspección de la vía y articular con los metrados obtenidos al Método PCI.

\subsection{Vía de prueba}

\subsubsection{Datos Generales de la Vía}

- Ubicación: Av. Separadora Industrial cuadras 8-10, Ate, Lima - Perú.

- Tipo de Pavimento: Flexible

- Longitud: $520 \mathrm{~m}$.

- Ancho de Calzada: 6 m.

- Configuración del tránsito: Autos, motos lineales, camiones, buses y camiones.

\subsection{Aplicación del Método $\mathrm{PCI}$}

\subsubsection{Muestreo y Unidades de Muestreo}

Según el método PCI (ASTM 6433), cada tramo de muestra debe tener un área entre el rango de $225 \pm 90 \mathrm{~m}^{2}$. Por ello, se ha tomado unidades de muestra de $240 \mathrm{~m}^{2}$ cada una, las cuales nos dan un total de 13 unidades de muestra en tramos de $40 \mathrm{~m}$.

Asimismo, el método considera un número mínimo de unidades de muestra a ser evaluadas, para obtener un nivel de confianza del 95\% del PCI, ésta se realiza mediante la siguiente ecuación:

$$
\mathrm{n}=\frac{\mathrm{N} \times \sigma^{2}}{\frac{\mathrm{e}^{2}}{4} \times(\mathrm{N}-1)+\sigma^{2}}
$$

Donde:

n: Número de unidades de muestra a evaluar

$\mathrm{N}$ : Número total de unidades de muestra en la sección

e: Error admisible en el estimado del PCI de la sección $(\mathrm{e}= \pm$ 5 puntos del PCI)

$\sigma$ : Desviación estándar del PCI entre las unidades.

Entonces:

$$
n=\frac{13 \times\left(10^{2}\right)}{\left(\frac{5^{2}}{4}\right) \times(13-1)+10^{2}} \approx 7
$$

Por lo tanto, las unidades de inspeccionar serán: UM1, UM3, UM5, UM7, UM9, UM11 y UM13, como se aprecia en la Figura 2. 
UNIDADES DE MUESTRA

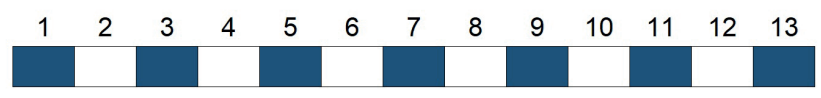

Unidad de muestra a inspeccionar

Unidad de muestra

Figura 2. Unidades de muestra a inspeccionar

\subsubsection{Levantamiento de fallas en campo}

El relevamiento de las fallas se realizó empleando hojas de inspección y catálogo de fallas de referencia. Asimismo, se empleó el equipo de protección personal adecuado y fue necesario cerrar parcialmente la vía utilizando conos de seguridad debido al tránsito de vehículos como se aprecia en la Figura 3.

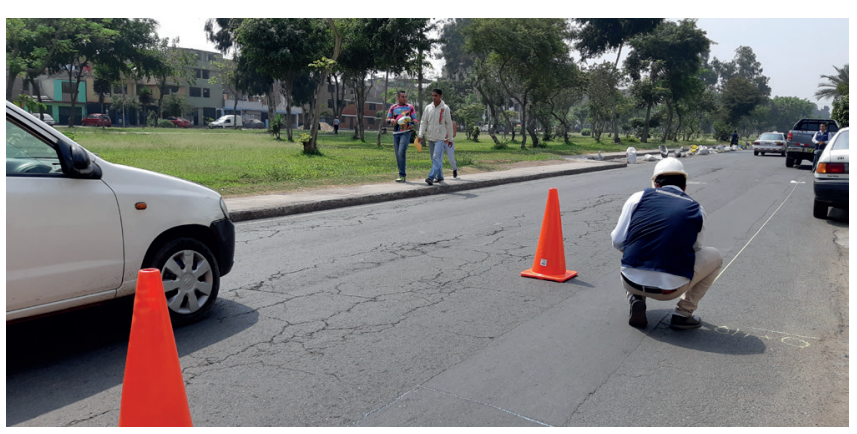

Figura 3. Inspección en campo

Se identificaron las fallas de las 7 unidades de muestra, determinando el tipo, grado de severidad y dimensiones como se muestra en la Figura 4. Los datos obtenidos se procesaron en gabinete para obtener el PCI en cada una de muestra.

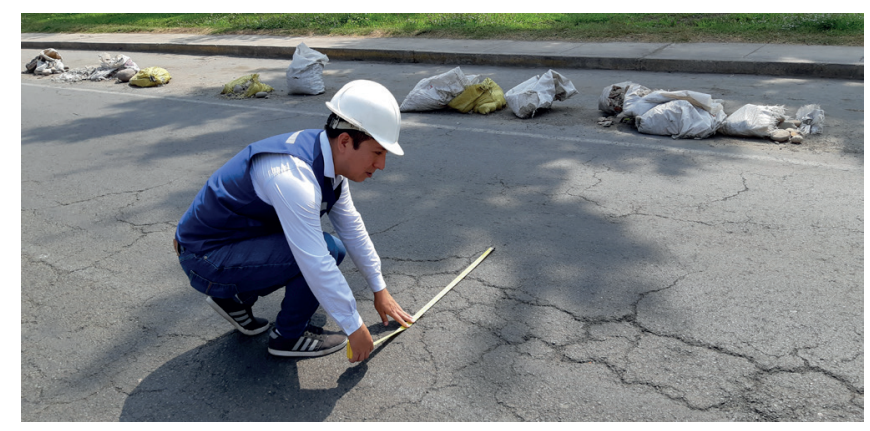

Figura 4. Medición de la falla identificada

\subsubsection{Rendimiento de la inspección}

El tiempo total de la inspección para las 7 unidades de muestra fue de 5 horas y media, iniciando a las 10:00 am y culminando a las 3:30 pm. El rendimiento de inspección promedio fue de 50 minutos por cada unidad de muestra de $40 \mathrm{~m}$ cada una, esto se debió a la cantidad de deterioros encontrados y al tránsito de vehículos. El personal de estuvo compuesto por 3 personas, de las cuales 2 fueron los evaluadores y un asistente para la toma de fotografías.

\subsection{Método VANT}

La presente metodología de evaluación consiste en dos etapas, una en campo y otra en gabinete. La etapa de campo consiste en relevar la información mediante un vuelo programado donde el VANT captura imágenes del estado superficial de la vía en estudio. Es importante resaltar que la persona quien realiza el vuelo debe ser un Operador o Piloto acreditado, con el fin de ejecutar un vuelo seguro y pueda tomar las decisiones acertadas frente a cualquier problema que se presente durante la ejecución del vuelo. La etapa de gabinete se basa en el procesamiento y análisis de las imágenes adquiridas para la obtención de ortofotos y modelos digitales en tres dimensiones que luego se usarán para la inspección del pavimento mediante el método PCI.

\subsubsection{Misión de Vuelo}

La misión o plan de vuelo se realiza mediante la aplicación DJI GS Pro, en la cual se delimita el área en estudio y se ingresa los parámetros de vuelo, para garantizar una resolución o GSD de $5 \mathrm{~mm}$ por pixel se programó la altura de vuelo a 20 $\mathrm{m}$. Asimismo, se considerado recubrimientos longitudinales y transversales de $80 \%$ en ambos casos para obtener mayor número de puntos homólogos y una mejor correlación de los mismos. El programa calcula automáticamente con los parámetros ingresados las líneas de vuelo, número de imágenes proyectadas y tiempo de vuelo como se aprecia en la Figura 5 y 6. 


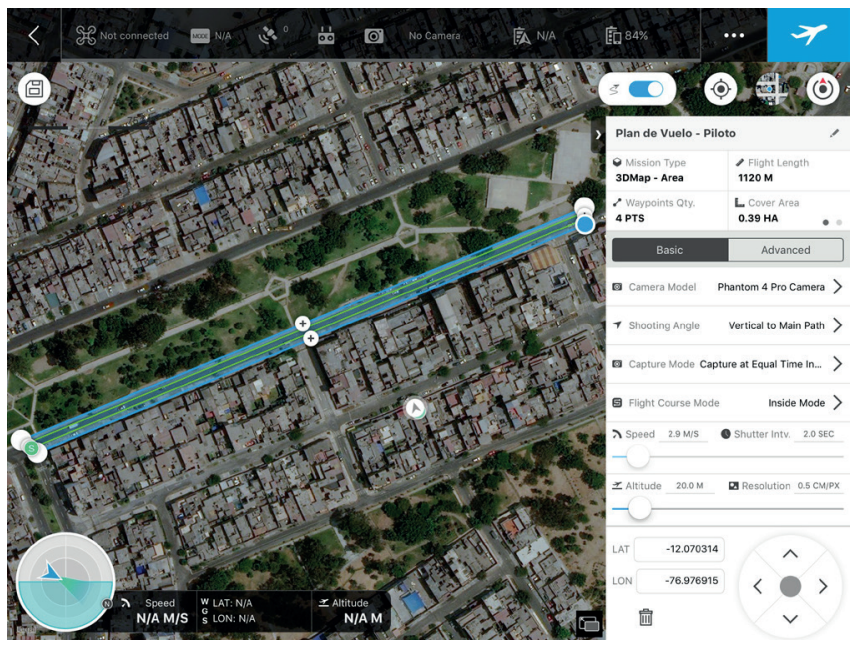

Figura 5. Configuración del plan de vuelo, parámetros de vuelo

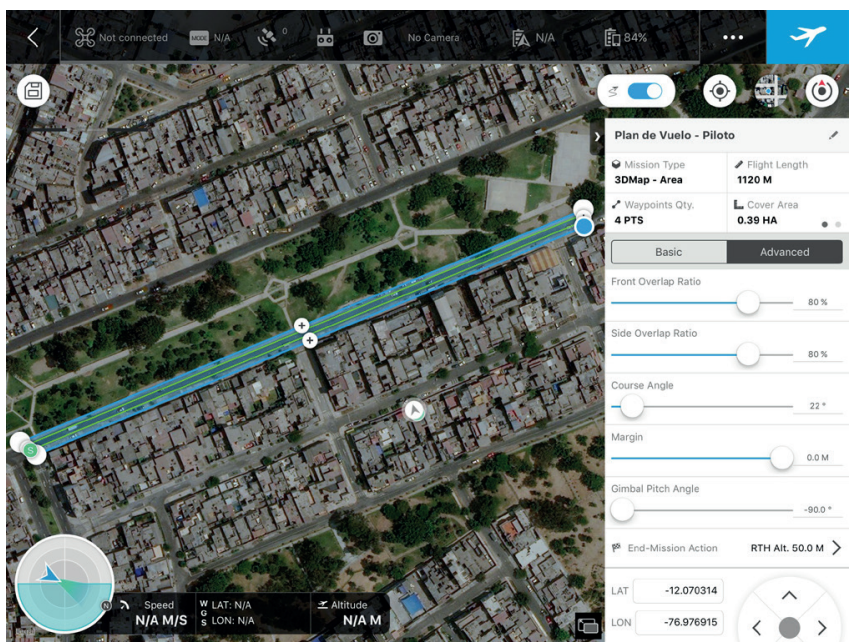

Figura 6. Configuración del plan de vuelo, traslapes

\subsubsection{Ejecución y Operación de Vuelo}

Para ejecutar el vuelo se escoge y delimita una zona de despegue dentro o fuera de la zona de estudio donde no exista obstáculo alguno para que el VANT pueda elevarse sin problemas como se muestra en la Figura 7. Para la realización del vuelo se realiza previamente un checklist que asegura la viabilidad del vuelo:

1. Hélices colocadas correctamente

2. Porcentaje de batería óptima tanto en el VANT como el radiocontrol.

3. Conexión correcta entre el radiocontrol y el VANT.

4. Buena recepción de señal de GPS (al menos 10 satélites)
5. Establecer punto de despegue y retorno en caso de pérdida de señal.

6. Tarjeta de memoria colocada correctamente.

7. Plan de vuelo cargado correctamente

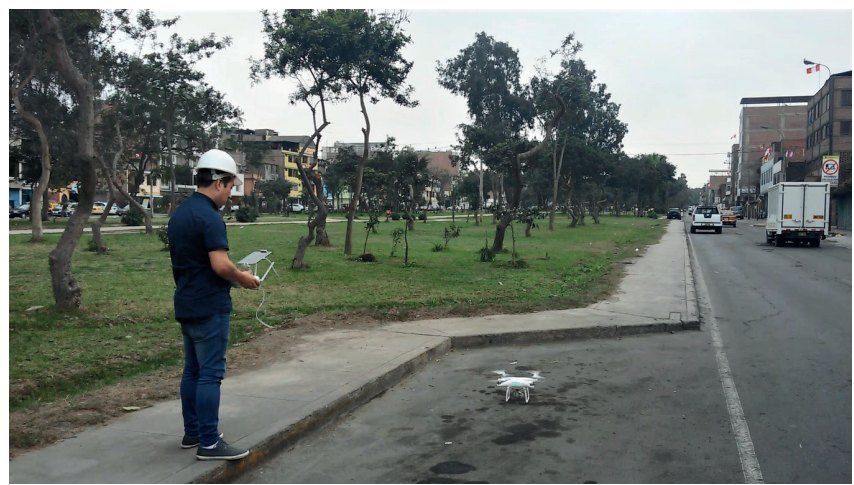

Figura 7. Ejecución del vuelo en zona de despegue

Una vez que el VANT despega, no es necesario el control manual alguno por parte del piloto, salvo se necesite cancelar el vuelo. Sin embargo, se puede monitorear en tiempo real la ubicación, velocidad, trayectoria, imagen de transmisión, número de satélites del GPS, cantidad de fotografías realizadas y porcentaje de la batería del equipo como se aprecia en la Figura 8.

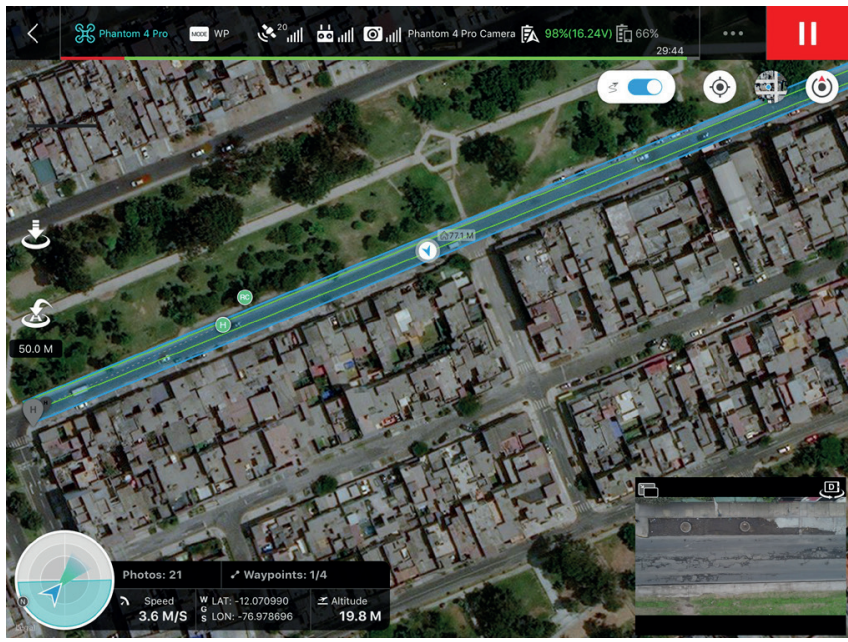

Figura 8. Monitoreo del plan vuelo

El tiempo total de vuelo desde el punto de despegue hasta el aterrizaje fue de 6 minutos con 50 segundos, obteniendo en total 145 imágenes georreferenciadas. 


\section{4 .3}

El procesamiento de las imágenes se realiza en gabinete mediante el software Pix4dMapper, se ingresan las imágenes obtenidas en el vuelo y se inicia el proceso fotogramétrico. Como primer paso el programa realiza el tratamiento inicial donde extrae automáticamente puntos clave de las imágenes para calcular la verdadera ubicación y los parámetros de cada imagen como se muestra en la Figura 9. Para el presente estudio se analizaron 145 imágenes con una resolución espacial de $5 \mathrm{~mm}$ por pixel.

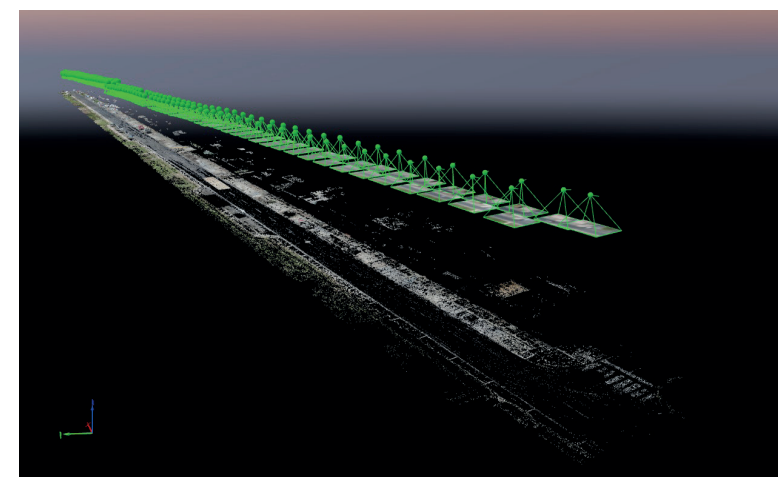

Figura 9. Ubicación de las fotografías

Luego densifica y filtra la nube de puntos de la zona de estudio para finalmente hacer la triangulación y obtener el modelo en 3D. Para nuestra vía en estudio se obtuvieron 29,708,344 puntos densificados como se muestra en la Figura 10 que dio como resultado el modelo 3D que se aprecia en la Figura 11.

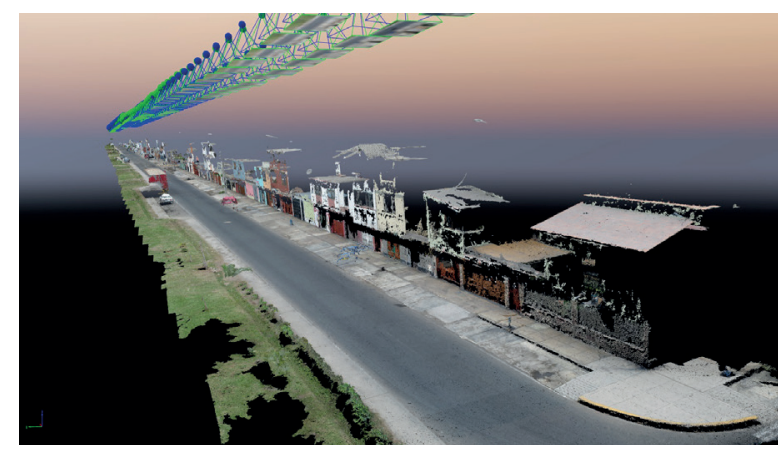

Figura 10. Nube de puntos densificada

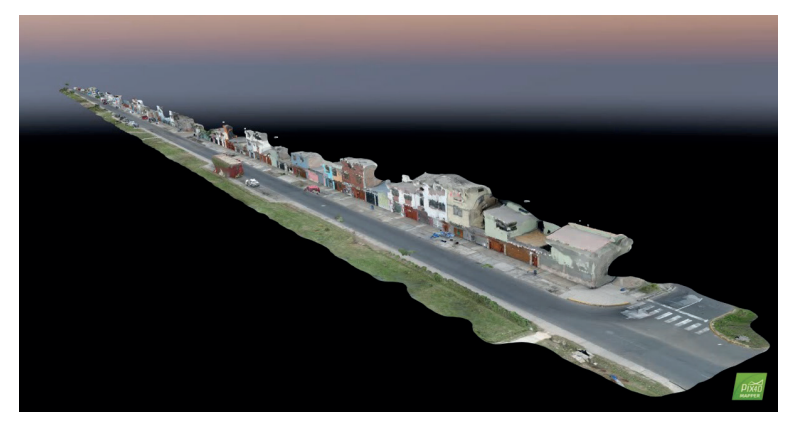

Figura 11. Modelo 3D de la zona de estudio
Como último paso el programa genera la ortofoto de toda la zona de trabajo con la resolución proyectada en el plan de vuelo y el modelo digital de superficie como se aprecian en las Figura 12 y Figura 13 respectivamente.

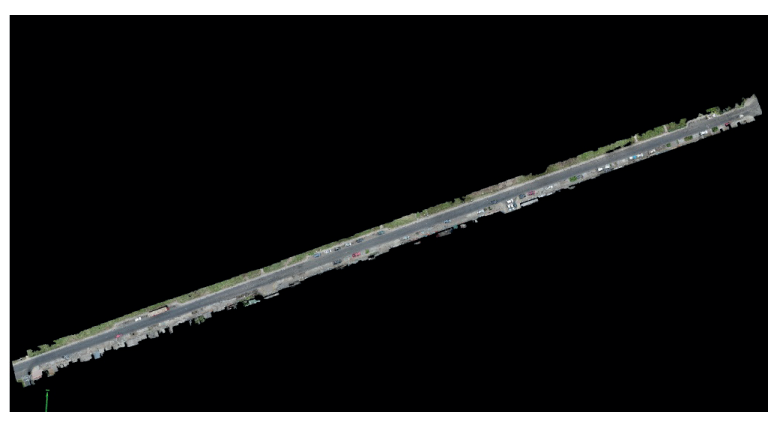

Figura 12. Ortofoto de la zona de estudio

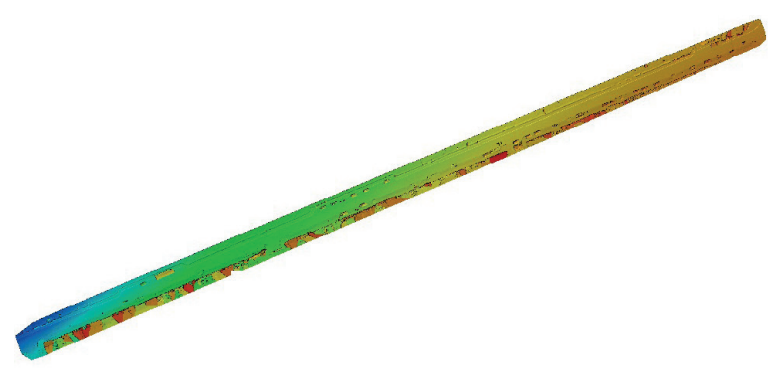

Figura 13. Modelo digital de Superficie

\subsubsection{Edición de la Ortofoto}

Es probable que en la ortofoto aparezcan vehículos o personas debido al usual tránsito en la vía, que nos impidan realizar la inspección en gabinete como se muestra en la Figura 14. Esto se debe a que en este método no es necesario cerrar parcial o totalmente la vía para ejecutar el vuelo. Sin embargo, el software permite realizar modificaciones ya que debido al recubrimiento longitudinal y transversal del vuelo cada región de la vía contiene más de una fotografía y, por tanto, la ortofoto es modificable fácilmente logrando una vía despejada como se observa en la Figura 15, para su posterior inspección.

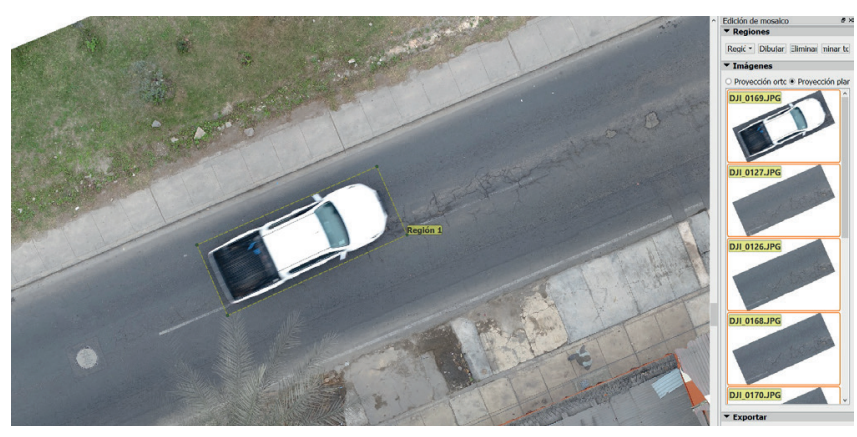

Figura 14. Ortofoto original con tránsito 

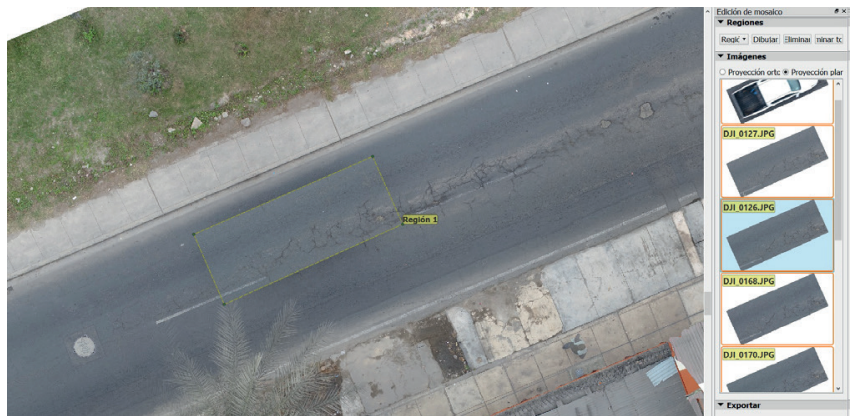

Figura 15. Ortofoto modificada sin tránsito

\subsubsection{Identificación y medición de las Fallas}

Con la ortofoto de gran resolución y el modelo en 3D se procede a realizar el inventario de fallas de las 13 unidades de muestra de manera visual, determinando la longitud o área según el tipo de falla y su grado de severidad como se muestra en la Figura 16. En el programa PIX4D Mapper o en CAD se puede terminar el ancho, longitud o área de cada deterioro.

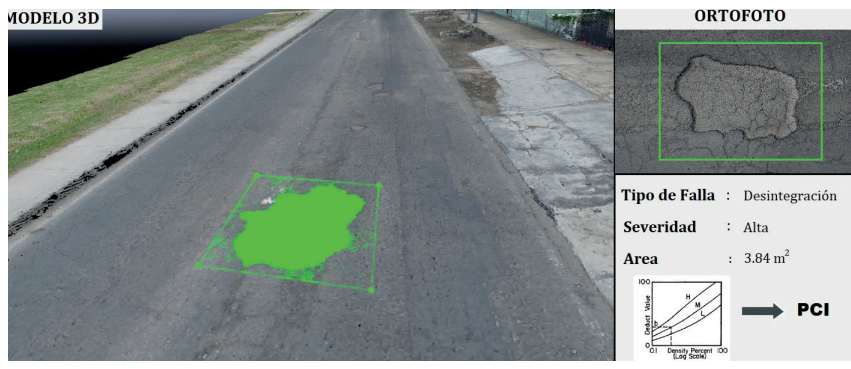

Figura 16. Identificación visual y metrado de fallas del pavimento

Asimismo, se introdujeron los datos de la inspección de cada unidad de muestra en una hoja de cálculo como se muestra en la Figura 17, indicando los diferentes tipos de fallas, severidad y cantidad de manera que se integre al Método PCI para finalmente determinar su condición.

Además, gracias a la ortofoto generada y la identificación de los deterioros, se puede elaborar planos de fallas de cada unidad de muestra, indicando el tipo de falla encontrada como su ubicación para su posterior mantenimiento correctivo como se aprecia en la Figura 18.

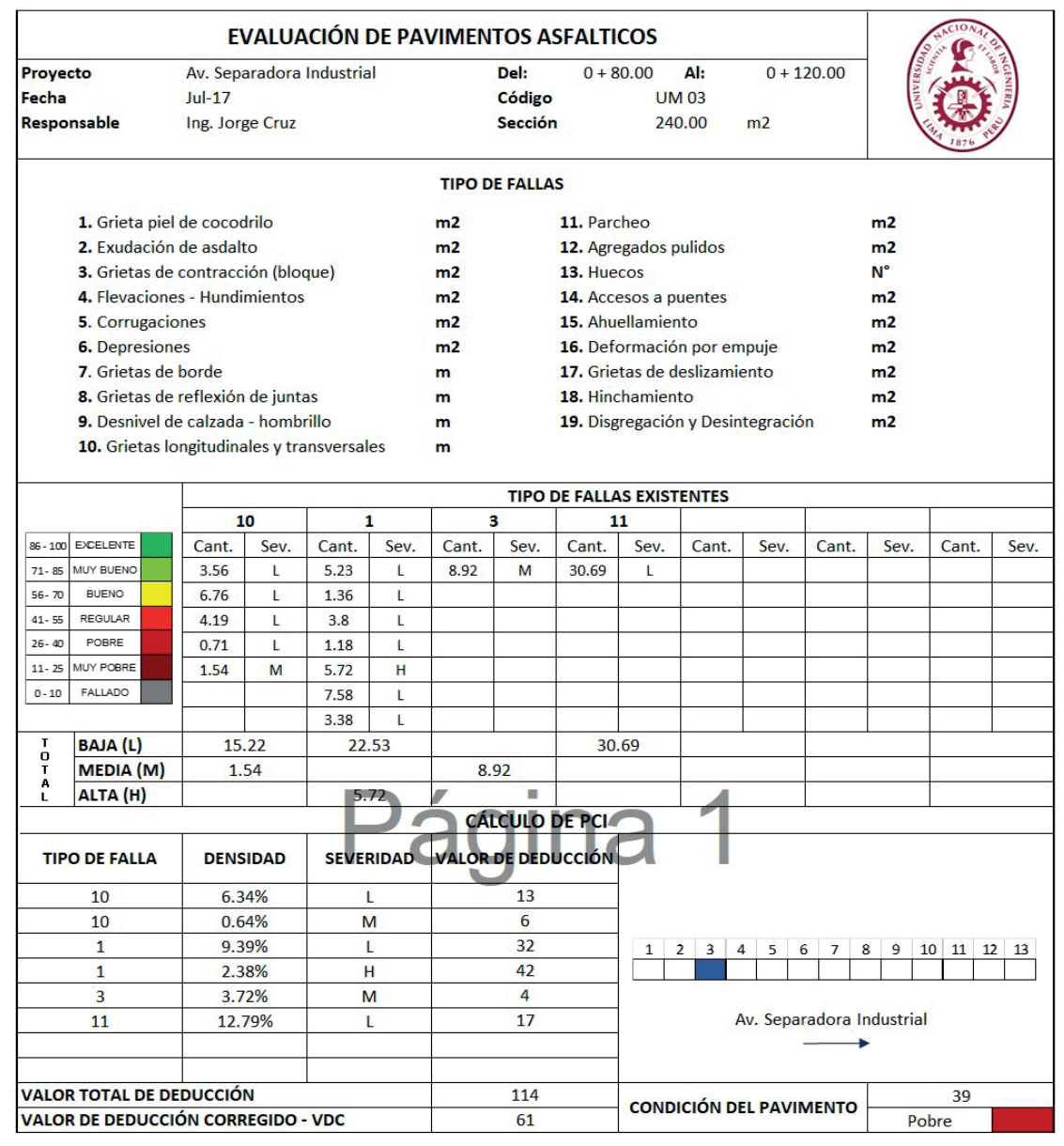



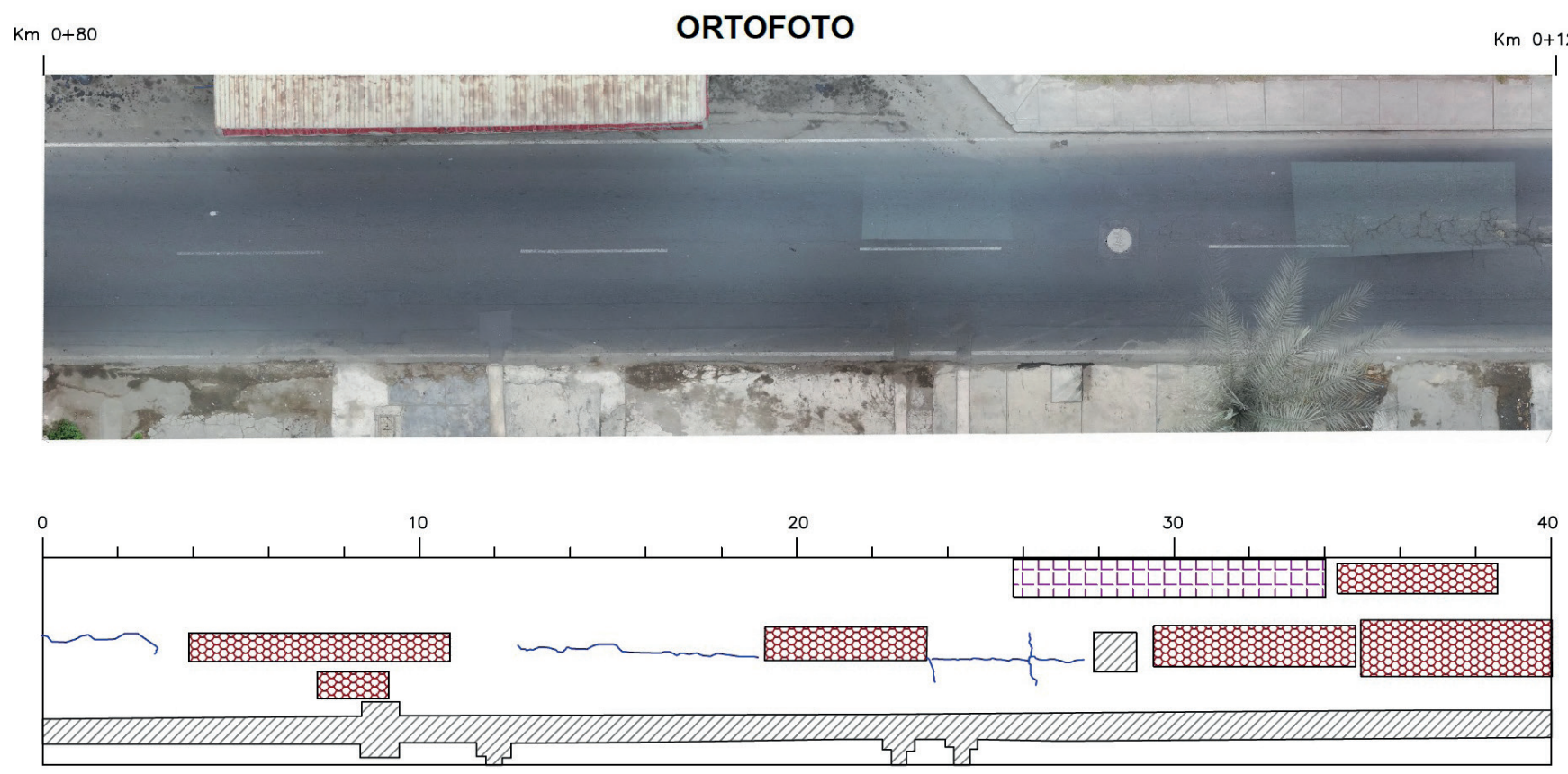

Figura 18. Plano de registro de fallas

El tiempo total de procesamiento, edición de la ortofoto e identificación de las fallas fue de 4 horas y media, obteniendo hojas de inspección y planos detallados de todas las unidades de muestra.

\section{RESULTADOS}

La Tabla 1, muestra la comparación entre los resultados obtenidos entre el Método tradicional PCI y el Método VANT. Cabe resaltar que en el método empleando imágenes del VANT se levantaron las fallas de las 13 unidades de muestra.

\begin{tabular}{|c|c|c|c|}
\hline & Método & Cl y VANT & \\
\hline $\begin{array}{l}\text { UNIDAD DE } \\
\text { MUESTRA }\end{array}$ & $\begin{array}{c}\text { PCI } \\
\text { MÉTODO } \\
\text { TRADICIONAL }\end{array}$ & $\begin{array}{c}\text { PCI } \\
\text { MÉTODO VANT }\end{array}$ & DIFERENCIA \\
\hline UM 01 & 54 & 54 & 0 \\
\hline UM 03 & 36 & 39 & 3 \\
\hline UM 05 & 18 & 18 & 0 \\
\hline UM 07 & 40 & 32 & -8 \\
\hline UM 09 & 26 & 24 & -2 \\
\hline UM 11 & 18 & 12 & -6 \\
\hline UM 13 & 59 & 58 & -1 \\
\hline
\end{tabular}

La Figura 19, muestra el plano con la clasificación según la condición de cada unidad de muestra obtenida de los resultados por el método VANT.

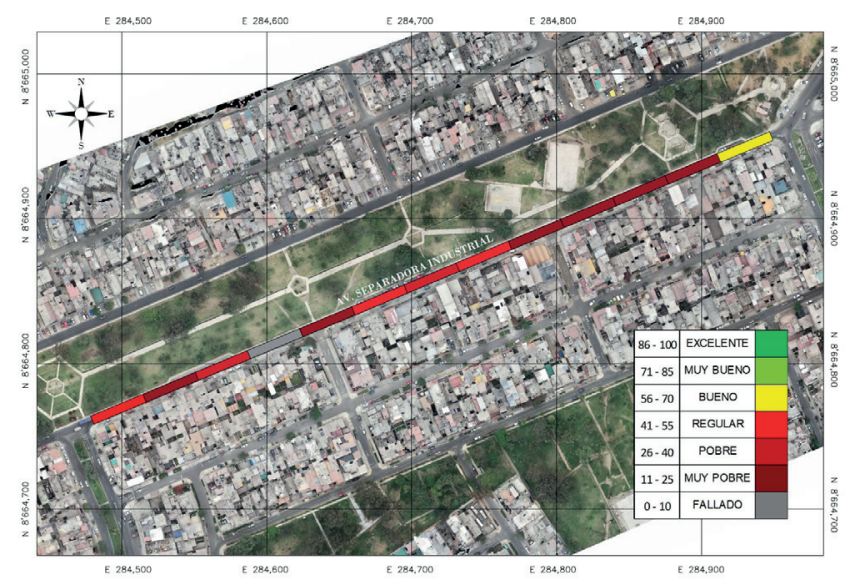

Figura 19. Plano de $\mathrm{PCI}$ de la zona evaluada

\section{DISCUSIÓN}

Los resultados obtenidos muestran valores cercanos de PCI, lo cual valida el método VANT, como una alternativa de evaluación de pavimentos mediante imágenes georreferenciadas. 
En relación a los rendimientos, con el método tradicional se evaluaron 7 unidades de muestra en un tiempo de 5 horas y media. Mientras que, con el Método VANT se levantó la información de las 13 unidades de muestra en 7 minutos, luego en gabinete el tiempo total de procesamiento, edición de la ortofoto, inspección y elaboración de planos fue de 4 horas y media. Esto demuestra una gran ventaja al emplear VANT para el relevamiento de la información con respecto al método convencional, el cual demanda mucho tiempo y requiere más personal para un mejor rendimiento, lo que eleva su costo.

No fue necesario cerrar parcial o totalmente la vía para ejecutar el vuelo, si bien es posible la aparición de vehículos en las imágenes obtenidas, éstos pueden ser modificados en la ortofoto, a fin de obtener una vía completamente despejada para la identificación de las fallas. Esto permite una evaluación de toda la vía, sin generar tráfico en la vía y sin poner en riesgo la vida de los inspectores.

La ortofoto de la zona de estudio permite la elaboración de planos de fallas indicando el lugar de cada falla con sus respectivos metrados para su futura intervención. Esto permite ubicar cada tipo de falla en campo y tener un registro que da la posibilidad de evaluar como se atendió el problema.

La información relevada por el VANT puede ser analizada cuantas veces sea necesaria sin necesidad de realizar otro vuelo, además, permite observar la evolución y aparición de nuevas fallas para tomar las decisiones correctivas adecuadas.

Por lo tanto, el relevamiento de información mediante fotografías obtenidas con VANT, permite la interpretación con fines de establecer estrategias de mantenimiento y rehabilitación, mediante una herramienta de toma de decisiones.

\section{CONCLUSIONES}

- La evaluación superficial de pavimentos empleando imágenes georreferenciadas obtenidas de un VANT es conveniente para gestionar actividades de mantenimiento y/o rehabilitación de las vías urbanas optimizando los recursos de los gobiernos municipales.

- El uso del vehículo aéreo no tripulado permite el levantamiento de información en corto tiempo, sin interrumpir el tráfico ni poner en riesgo la vida de los inspectores en comparación con el método convencional.
- La edición de la ortofoto permite evaluar toda la vía de estudio, ubicando cada falla, severidad y su cantidad correspondiente, que articula como insumo con el método PCI.

- La información relevada por el VANT puede ser reproducible en cualquier momento a fin de analizar la evolución de las fallas en el tiempo y establecer las medidas preventivas de conservación.

- El método VANT permite una inspección más rápida, generando información fidedigna del estado existente del pavimento, además se puede elaborar planos que acompaña a los metrados para priorizar el mantenimiento de las zonas de bajo índice de condición.

- La evaluación superficial de pavimentos empleando imágenes georreferenciadas es conveniente para gestionar actividades de mantenimiento y/o rehabilitación de las vías urbanas.

\section{RECOMENDACIONES}

- Es recomendable realizar la misión de vuelo con anticipación considerando la geometría y topografía del lugar a evaluar, de tal manera de elegir la altura de vuelo apropiada.

- Se recomienda ejecutar el vuelo en días de poco tránsito, entre las 8:00 am y las 2 pm, de manera que las imágenes obtenidas no sean afectadas por sombra o varios obstáculos.

- Se sugiere realizar el inventario de fallas en períodos de 6 a 12 meses, con la finalidad de identificar la aparición de nuevos daños y analizar la evolución de las fallas existentes para la toma de decisiones de trabajos correctivos.

- Comprobar la metodología en otras vías, que perfeccione el proceso y se ajuste a un algoritmo de interpretación de vistas georreferenciadas.

- Se debe tener en cuenta el rendimiento de las baterías de los VANT, si bien su rendimiento es limitado actualmente, la tecnología de estos se encuentran constante mejora, lo que demuestra su alto potencial para la inspección de activos viales.

- Se recomienda contar con pilotos acreditados para el planeamiento como ejecución del vuelo, asimismo, tener en cuenta los permisos necesarios para realizar el levantamiento de información en áreas urbanas. 


\section{REFERENCIAS}

American Society for Testing Materials (2016). Standard Practice for Roads and Parking Lots Pavement Condition Index Surveys ASTM D6433-16, West Conshohocken, Estados Unidos.

- Gutierrez W. (2016). Mecánica de Suelos Aplicada a las Vías de Transporte. Editorial Macro, Lima, Perú.

Martinez P., Ojeda D., Perez E., \& Brazo F. (2009). "Vehículos Aéreos No Tripulados (Vant) En Cuba, Aplicados A La Geomática, Estado Actual, Perspectivas y Desarrollo". Cuba.

Zhang C. \&Elaksher A. (2012). "An unmanned aerial vehicle-based imaging system for 3D measurement of unpaved road surface distresses". Computer-Aided Civil and Infrastructure Engineering, Vol 27, Issue 2. Pp. 118-129. Estados Unidos. 